\title{
Development of a Structured Interview Tool to Help Patients Identify and Solve Rheumatic Condition-Related Work Barriers
}

\author{
SARALYNN ALLAIRE AND JULIE J. KEYSOR
}

Objective. To develop a comprehensive and efficient assessment tool for rheumatic condition-related work barriers and explore its use by physical and occupational therapists.

Methods. Literature on arthritis work barriers was examined, followed by the collection of qualitative data on work barriers from patients with rheumatic conditions. A tool called the Work Experience Survey-Rheumatic Conditions (WES-RC), which identifies barriers and facilitates the formation of solutions for barriers, was developed using this data. Ten physical and occupational therapists reviewed the initial version of the tool and provided qualitative data and the relevance of its use by therapists. Using this data, the WES-RC was revised. The therapists then administered the WES-RC to 20 patients. Quantitative data, qualitative data, and results of the administrative experience were collected from therapists after each administration. Relevant data were used to further revise the WES-RC. Qualitative data were coded and themes developed by 2 readers and compared. Means and frequencies were used to describe the quantitative data. Results. The WES-RC addressed patients' work barriers quite well with a mean score of 8.7, on a scale of 1-10 where 10 = barriers completely covered, and administration time was reported as "about right" in 18 (90\%) of 20 administrations. Eighty percent of the therapists' administration experiences were positive. Therapists reported barrier identification as easy, while solution formation was difficult in $45 \%$ of the administrations and judged insufficient in $35 \%$.

Conclusion. The WES-RC appears to be feasible for rheumatology patients and for use by physical and occupational therapists. Further study is needed to enhance effective solution formation.

\section{INTRODUCTION}

More than $5 \%$ of US employment-age adults report an arthritis-attributable limitation in their ability to work (1). Work disability associated with arthritis and other rheumatic conditions can be prevented by intervention that helps patients overcome health-related work barriers (problems) (2). Unfortunately, such intervention is largely unavailable (3), and therefore is an unmet critical need of patients with rheumatic conditions. Health professionals may be able to help fill this gap. Varekamp et al note that, "Health professionals are in a position to identify patients

Supported by a Health Professional Investigator Award from The American College of Rheumatology Research and Education Foundation.

Saralynn Allaire, ScD, Julie J. Keysor, PhD, PT: Boston University School of Medicine, Boston, Massachusetts.

Dr. Keysor has received consultant fees, speaking fees, and/or honoraria (less than $\mathbf{\$ 1 0 , 0 0 0 )}$ from the American Physical Therapy Association.

Address correspondence to Saralynn Allaire, ScD, Clinical Epidemiology Research and Training Unit, X200, 650 Albany Street, Boston, MA 02118. E-mail: sallaire@bu.edu.

Submitted for publication December 9, 2008; accepted in revised form March 23, 2009. at risk for work disability and to discuss work-related problems and solutions with these patients" (4).

Health professionals could more readily help patients with their work-related problems if they had an assessment tool that was specific to rheumatic conditions and efficient to use. Several methods and tools are available for identification of health work barriers and solution formation (5-7). The ability of health professionals to use these methods or tools is limited, since some require that information be gathered at the worksite, and others require vocational skills that are not within the skill repertoire of most health professionals. In addition, most of these tools are not specific to rheumatic conditions. Two tools that are specific to rheumatic conditions, however, have recently been developed. The first, the Work Instability Scale, assesses the level of work instability related to rheumatoid arthritis rather than particular barriers (8). The second, the Ergonomic Assessment Tool for Arthritis (9), assesses work station and work task barriers only and may not include barriers unique to other rheumatic conditions, such as the effect of fluorescent lighting on systemic lupus erythematosus.

A structured interview tool called the Work Experience Survey (WES) (10) offers the following advantages: it can 
be administered anywhere, it addresses a broad range of workplace barriers (in addition to work station and task barriers), and it was designed for all types of disabilities. The WES is administered through a face-to-face or telephone interview. After collecting background information, an administrator helps the patient identify work barriers from checklists, prioritize barriers by significance, and form solutions for the most significant barriers. Validity of the WES is demonstrated through studies that confirm its theoretical base and show that barriers vary according to disabilities' unique effects (10).

However, there are 2 major disadvantages of the WES for patients with rheumatic conditions. First, since the WES was designed for all types of disabilities, it likely lists barriers extraneous to rheumatic conditions, which would reduce its efficiency when used for patients with these conditions. In addition, some barriers reported in the literature for patients with rheumatic conditions (11) are not listed on the WES. Secondly, although it assesses a broad range of workplace barriers, it does not include non-workplace barriers, such as commuting difficulty, which are important predictors of rheumatic condition work disability (11).

The primary purpose of our study was to modify the WES so that it comprehensively, yet efficiently, assesses work barriers associated with rheumatic conditions. In addition, we explored the perceptions of physical and occupational therapists toward the quality, feasibility, and practice relevance of using a modified WES with their patients.

\section{MATERIALS AND METHODS}

Design. We used a 3-step process to obtain data and modify the WES. First, we reviewed the literature on rheumatic condition work barriers. Because the relevant literature was sparse, we decided to use a primarily qualitative and exploratory approach to gather further data. Therefore, our second step was to collect qualitative data directly from patients about work barriers and use this data to create a modified WES, which we called the Work Experience Survey for Persons with Rheumatic Conditions (WES-RC). In the third step, we obtained qualitative and quantitative data about the WES-RC from physical and occupational therapists and used it to refine the WES-RC and explore their use of the tool with patients. The study was approved by the Boston University Medical Center Institutional Review Board.

Literature review. We initially searched MEDLINE and PsychInfo databases using the terms "arthritis" or "lupus erythematosus" and "work barriers" or "work problems." Since there were few citations using these terms, we broadened the search by including the term "work disability."

Qualitative patient subject data on work barriers. Thirty-two employed patients with a wide variety of rheumatic conditions participated. The patient characteristics are

\begin{tabular}{|c|c|}
\hline Characteristic & No. \\
\hline Age, mean (range) years & $45(22-64)$ \\
\hline \multicolumn{2}{|l|}{ Sex } \\
\hline Female & 30 \\
\hline Male & 2 \\
\hline \multicolumn{2}{|l|}{ Race/ethnicity } \\
\hline White & 25 \\
\hline African American & 5 \\
\hline Hispanic & 2 \\
\hline \multicolumn{2}{|l|}{$\begin{array}{l}\text { Rheumatic conditions (includes comorbid } \\
\text { conditions) }\end{array}$} \\
\hline Fibromyalgia & 8 \\
\hline Osteoarthritis & 7 \\
\hline Rheumatoid arthritis & 5 \\
\hline Systemic lupus erythematosus & 4 \\
\hline Juvenile arthritis & 4 \\
\hline Systemic sclerosis & 3 \\
\hline Sjögren's syndrome & 3 \\
\hline Psoriatic arthritis & 2 \\
\hline $\begin{array}{l}\text { Mixed connective tissue disorder, } \\
\text { dermatomyositis, ankylosing } \\
\text { spondylitis, polymyalgia rheumatica, } \\
\text { arthritis }\end{array}$ & 1 each \\
\hline \multicolumn{2}{|l|}{ Occupation } \\
\hline Professional/managerial & 11 \\
\hline Registered nurse & 3 \\
\hline Manager & 4 \\
\hline $\begin{array}{l}\text { Teacher, loan officer, market } \\
\text { researcher, kitchen designer }\end{array}$ & 1 each \\
\hline Blue/pink collar & 21 \\
\hline Food service worker & 4 \\
\hline Administrative assistant & 3 \\
\hline Childcare worker & 3 \\
\hline Clerk & 3 \\
\hline Customer service worker & 2 \\
\hline $\begin{array}{l}\text { Nursing assistant, telephone surveyor, } \\
\text { teacher aide, research assistant, } \\
\text { cashier, lab technician }\end{array}$ & 1 each \\
\hline
\end{tabular}

shown in Table 1. Sixteen subjects attended 1 of 2 focus groups. The remaining 16 subjects were interviewed by telephone. Patient subjects were recruited from rheumatology practices to participate in a focus group or individual telephone interview, and a semistructured qualitative approach was used for both the focus groups and interviews. We prepared a script based on the scientific literature and consultation from WES author Richard Roessler (10). The structure of the focus groups and interview sessions began with open-ended questions about work barriers created by the patient's rheumatic condition and proceeded to specific questions based on WES sections and on the scientific literature. The same investigator (SA) conducted all sessions. The sessions were audio taped, and the material was transcribed by a transcriptionist.

To analyze the transcripts, we used a modified approach to the Strauss and Corbin (12) analysis of grounded theory. First, all statements made by participants were reviewed and barriers were identified. Second, the coding responses of specific barriers were categorized into themes. Third, 
rather than performing a detailed analysis of the themes as described by Straus and Corbin (12), we grouped together barriers that represented conceptually similar domains and then compared the domains and barriers with WES barrier categories and individual barriers. New categories were created for statements about barriers that did not fit WES categories. Within the categories that were similar to WES categories, we compared barriers described by our subjects with those on the WES and noted similarities and differences. This categorization and barrier placement was done iteratively, beginning after the first focus group and half of the individual interviews were completed. The barriers and categories were reviewed, combined, or relabeled and new categories formed as needed.

Qualitative and quantitative data obtained from therapists. Physical and occupational therapists were recruited from 2 large urban hospital outpatient units. Ten therapists participated, 5 in each outpatient unit. Two of 6 physical therapists were men, and the remaining physical therapists and all 4 occupational therapists were women.

Data collection was completed at the first unit before proceeding to the second. After each session of data collection, findings relevant to the WES-RC were incorporated, and a revised draft was formed and used in the subsequent data collection session.

In each unit, an investigator (SA) first conducted a focus group with the unit's therapists. Therapists were asked to comment on WES-RC content, anticipate administration problems, and discuss the relevance of WES-RC use to therapist practice. The focus groups were audio taped, and the tapes transcribed by a transcriptionist. We reviewed the transcripts to identify therapists' perceptions of the WES-RC and its use in clinical care.

Each therapist then administered the WES-RC to 2 different employed patients with a rheumatic condition; the administrations were conducted 4-8 weeks apart. The purposes of this testing were to obtain further input on WES-RC content, assess administration issues, assess the ease and efficiency of use, and further examine the relevance of WES-RC use to therapist practice. Administration instructions had been given during the focus groups, but written instructions were provided as well. In addition to the WES-RC tool, therapists were given a list of potential resources for referral, such as the Massachusetts StateFederal Vocational Rehabilitation program, to refer patients needing further help.

Following each administration, therapists filled out a brief questionnaire that ascertained how well the WES-RC assessed the patient's work problems (content), the degree of difficulty the therapist experienced in forming solutions (practice relevance), and the overall user friendliness of the tool. Visual analog scales using ratings of 1-10 were used to assess each area. Satisfaction with the amount of time it took to administer the WES-RC was also assessed. Response options were "too long," “about right," or "too short." Therapists also recorded the time that administration of the WES-RC began and ended.
The same investigator (SA) conducted an individual structured interview with therapists after each administration to gather more information about their experience. Specific guiding questions were used to ascertain therapists' perceptions related to the WES-RC and its content (e.g., comprehensiveness or missing items), issues with formation of solutions for barriers, ease of using the WES$\mathrm{RC}$, and the administration time requirement. The participants were also asked to describe their overall experience and identify any issues or recommendations concerning the WES-RC. Lastly, the patient's WES-RC form was reviewed with the therapist.

The quantitative questionnaire data from the first 10 and second 10 administrations were separately combined and examined for differences possibly due to WES-RC revision or administration experience. Means or frequencies were calculated.

Therapists' comments from the face-to-face interviews were reviewed by 2 investigators (SA, JJK) to identify responses to the guiding questions pertaining to use and assessment of the WES-RC. We then rated each administration experience as positive or negative based on therapists' responses to the question on overall administration experience. We also evaluated the sufficiency of the solutions formed for each patient by examining therapists' quantitative rating of solution formation difficulty, their qualitative comments about solution formation, and our review of the solutions formed for patients' problems as written on the WES-RC forms. We rated solution formation as "sufficient," "partially sufficient," or "insufficient."

\section{RESULTS}

Review of literature. At the time the search was conducted, we found only 2 studies whose purpose was to describe specific rheumatic condition work barriers $(13,14)$. In the first study, barriers were confined to those assessed by the WES, and the most common barriers were handling objects, prolonged sitting, working for 8 hours, kneeling, raising arms above shoulder level, using hands, repetitive work, writing, performing under stress or deadlines, and cold temperatures (13). In the second study, patients cited several barriers not listed in the WES including maintaining a pleasant disposition, working overtime, traveling for business, being on time, getting ready for work, and commuting to and from work (14). Several of these barriers indicate that it is important to assess barriers that exist out of the workplace, as well as those in the workplace. When we broadened our review of the literature to risk factors related to "work disability" among persons with arthritis or systemic lupus, we found work pace, as well as supervisor and coworker support issues, frequently mentioned as barriers (11,15-21). All of these barriers were slated for inclusion on a modified WES.

Patient subject data. There were substantial differences between the work barriers cited by our patient subjects and those found on the WES. Three new themes emerged that 
indicated new categories of barriers were needed. These new themes were medical issues, energy issues, and issues that occurred outside the workplace but still affected work. The latter theme included getting ready for work, work-related travel, and balance between work and home life. Disability identity and disclosure issues emerged as a fourth theme and showed that our subjects' issues related to working with others differed from those on the WES. These issues were categorized on the WES as social job demand barriers, and they tended to concern working alone or around others rather than disability identity or disclosure. Other differences included work barriers that were on the WES but not cited by the subjects, or barriers that were similar but differently qualified, such as standing all day (WES) versus any standing (subjects).

We made 3 types of modifications to WES barriers (Table 2). The first was to add new categories of barriers: getting ready for work; traveling to and from (or for) work; time, energy, and emotional job demands; and balance between work and home life. The second modification was to replace the existing WES barrier categories that were seldom or never cited with those frequently cited by subjects. In the WES social job demand category, most of the original barriers were replaced. Because of this replacement, and the different nature of barriers cited by our subjects, we renamed this category as relationships with others at work. Since subjects rarely cited barriers in the job mastery concerns and job satisfaction categories on the WES, these sections were reduced substantially. The third modification was to specify or alter existing barriers in some way. For example, entrance was specified as door weight and turning doorknobs.

In addition to barrier changes, we replaced the disability effects portion of the WES background section with rheumatic symptoms and general health issues. Symptoms cited by patient subjects were pain, fatigue or lack of stamina, various medication effects, and the episodic nature of symptoms. Health issues included sleep difficulties, stress or worry, and depression. A draft of the WES-RC was created using all of these modifications.

Therapist subject data. WES-RC content. Several therapists stated that the content of the WES-RC barrier checklists was comprehensive, and the barrier examples helped patients identify and verbalize problems. A few missing barriers (i.e., turning key in ignition, checking rearview mirror, and problems talking due to dry throat) were identified. Therapists rated the WES-RC as addressing patients' barriers quite well with a mean of 8.5 (range 6-10 on a scale of 1-10 where $10=$ completely addressed all problems), on the first administration and a slight increase to a mean of 9.0 (range $8-10$ ) on the second administration (Table 3). For the final lists of potential barriers on the WES-RC, see Supplemental Appendix A, available in the online version of this article at http://www3. interscience.wiley.com/journal/77005015/home.

Administration issues and ease of use. In the focus groups, therapists perceived the WES-RC as being easy to use even without instructions. After administering the WES-RC, they reported that the barrier checklists helped redirect talkative patients. Several wording and formatting changes were suggested and implemented. Therapists rated WES-RC user friendliness as a mean of 8.6 (range $6-10$, on a scale of 1-10 where $10=$ very user friendly), and a mean of 9.1 (range 8-10) after the first and second administrations, respectively. In the focus groups, therapists perceived that WES-RC administration would take 60-90 minutes. Actual overall mean administration time was 44 minutes (range 25-60). In 90\% of administrations, this time was viewed as "about right." The time for the other 2 administrations was viewed as "too long," although the times of 45 minutes and 60 minutes were within the range.

Relevance to practice. In the focus groups, all 10 therapists immediately stated that addressing patients' healthrelated work problems was relevant to their practice. This was followed by some equivocation. Physical therapists especially felt this work would not fit the reason for referral, yet it was noted that referral reasons are often vague, and that the WES-RC might help in functional goal setting. Several therapists expressed concern about being able to suggest solutions, especially about work relationship issues. One therapist stated, "We don't really think much about work relationship problems, but patients bring these problems up." After administering the WES-RC to patients, one physical therapist decided WES-RC use was not within physical therapy scope of practice.

We judged the WES-RC use experience as positive in 16 of $20(80 \%)$ interviews. Negative experiences stemmed from difficulty in forming solutions for the patient's barriers, or from difficult patients. While barrier assessment was reported as easy, therapists reported difficulty forming solutions in 9 of 20 (45\%) administrations. Mean perception of how hard it was to form solutions was 4.3 (range $1-7$, on a scale of $1-10$ where $10=$ very hard), and 4.6 (range 1-8) on the first and second administrations, respectively. Solutions formed for patients' barriers were judged as sufficient in $9(45 \%)$ of 20 administrations, partly sufficient in $4(20 \%)$ of 20 administrations, and insufficient in 7 (35\%) of 20 administrations.

The first source of difficulty with solution formation was that the patient's barriers were perceived as outside the therapists' scope of practice. Work relationship and disability identity, and disclosure issues, were especially likely to be viewed this way. Lack of familiarity with types of job accommodations was the second source of solution formation difficulty; the only accommodation recognized for prolonged standing was taking breaks. The third source of difficulty was discomfort with solution formation by patients. Although WES instructions clearly indicate that solution formation is intended to be done mutually by the patient and administrator, one occupational therapist felt strongly that it was the therapist's role to develop the solutions. On the other hand, several therapists reported being pleased when patients suggested solutions. However, when solution formation was done primarily by the patient, therapists said they felt they hadn't helped the 


\begin{tabular}{|c|c|c|c|}
\hline WES Section & New on WES-RC & Deleted from WES & $\begin{array}{c}\text { Altered or specified on } \\
\text { WES-RC }\end{array}$ \\
\hline Background & Medication issues & Cause of disability & $\begin{array}{l}\text { Disability changed to health; } \\
\text { disability effects specified } \\
\text { to symptoms and general } \\
\text { health issues }\end{array}$ \\
\hline Accessibility & & $\begin{array}{l}10 \text { items, e.g., water } \\
\text { fountains, warning } \\
\text { devices, identification } \\
\text { signs/labels; } 3 \text { items } \\
\text { combined/relocated to } \\
\text { working conditions }\end{array}$ & $\begin{array}{l}\text { Entrance specified to door } \\
\text { weight and turning door } \\
\text { knobs }\end{array}$ \\
\hline $\begin{array}{l}\text { Essential job } \\
\text { functions: } \\
\text { physical job } \\
\text { demands }\end{array}$ & $\begin{array}{l}\text { Getting up and down from sitting; } \\
\text { carrying things; squatting/bending/pick } \\
\text { things up from low positions; computer } \\
\text { use issues; body position issues; being } \\
\text { able to move quickly; } \\
\text { strength/endurance issues }\end{array}$ & Much talking; hearing well & $\begin{array}{l}\text { Qualifiers eliminated, e.g., } \\
\text { standing all day changed } \\
\text { to standing or being on } \\
\text { feet too long, and weight } \\
\text { lift limits; hand use items } \\
\text { changed from individual } \\
\text { or both hands to types of } \\
\text { tasks, e.g., holding, } \\
\text { manipulating, and writing }\end{array}$ \\
\hline $\begin{array}{l}\text { Essential job } \\
\text { functions: } \\
\text { cognitive job } \\
\text { demands }\end{array}$ & $\begin{array}{l}\text { Staying alert; focusing/concentrating on } \\
\text { work activities }\end{array}$ & Judgment & $\begin{array}{l}\text { Label changed to mental job } \\
\text { demands; memory items } \\
\text { combined to short-term } \\
\text { memory; thought } \\
\text { processing changed to } \\
\text { thinking quickly; planning } \\
\text { and organizing combined }\end{array}$ \\
\hline $\begin{array}{l}\text { Essential job } \\
\text { functions: task- } \\
\text { related job } \\
\text { demands }\end{array}$ & & $\begin{array}{l}\text { Variety of duties; little } \\
\text { feedback on } \\
\text { performance; read } \\
\text { written instructions; able } \\
\text { and licensed to drive; } \\
\text { follow written } \\
\text { instructions }\end{array}$ & $\begin{array}{l}\text { As all other items were } \\
\text { moved to or combined } \\
\text { with items in other } \\
\text { sections, this section was } \\
\text { eliminated }\end{array}$ \\
\hline $\begin{array}{l}\text { Essential job } \\
\text { functions: social } \\
\text { job demands } \\
\text { (renamed } \\
\text { relationships with } \\
\text { others at work) }\end{array}$ & $\begin{array}{l}\text { Perceived need to hide } \\
\text { condition/symptoms; need to handle } \\
\text { reactions of others to health condition; } \\
\text { lack of understanding; resentment } \\
\text { about time off; feeling self-conscious } \\
\text { about symptoms/appearance; feeling } \\
\text { guilty about taking time off }\end{array}$ & $\begin{array}{l}\text { Working alone; working } \\
\text { around others; working } \\
\text { with hostile others }\end{array}$ & $\begin{array}{l}\text { Working with others } \\
\text { specified to help needed } \\
\text { issues; supervising others } \\
\text { specified to reactions of } \\
\text { people you supervise; } \\
\text { interactions with } \\
\text { supervisors specified to } \\
\text { supervisors/management } \\
\text { not supportive }\end{array}$ \\
\hline $\begin{array}{l}\text { Essential job } \\
\text { functions }\end{array}$ & $\begin{array}{l}\text { New barrier category added: time, energy } \\
\text { and emotional job demands, which } \\
\text { includes: working required hours; } \\
\text { working extra/overtime hours; starting } \\
\text { work soon after arrival; scheduling/ } \\
\text { work pace issues; meeting } \\
\text { time/production deadlines or perform } \\
\text { under stress; emotional demands of } \\
\text { working with children/customers }\end{array}$ & & \\
\hline Working conditions & Fluorescent/sunlight & $\begin{array}{l}\text { Wet or slippery surfaces; } \\
\text { obstacles in path; dust; } \\
\text { noise, always inside }\end{array}$ & $\begin{array}{l}\text { Cold temperature specified } \\
\text { to include air } \\
\text { conditioning and working } \\
\text { outdoors; fumes and odors } \\
\text { combined and specified to } \\
\text { include smoke and scents } \\
\text { (continued) }\end{array}$ \\
\hline
\end{tabular}




\begin{tabular}{|c|c|c|c|}
\hline \multicolumn{4}{|c|}{ Table 2. (Cont'd) } \\
\hline WES Section & New on WES-RC & Deleted from WES & $\begin{array}{c}\text { Altered or specified on } \\
\text { WES-RC }\end{array}$ \\
\hline Company policies & $\begin{array}{l}\text { No opportunity to do some work at } \\
\text { home; lack of support for time off for } \\
\text { health care appointments }\end{array}$ & $\begin{array}{l}\text { Inflexible/vague job } \\
\text { descriptions; infrequent } \\
\text { review of job } \\
\text { descriptions }\end{array}$ & $\begin{array}{l}\text { Inflexible work schedules } \\
\text { specified to need to arrive } \\
\text { at set time; no flexibility } \\
\text { in work hours or } \\
\text { opportunity to take rest } \\
\text { breaks; rigid sick/vacation } \\
\text { leave policies specified to } \\
\text { inadequate number of } \\
\text { days, periodic need to } \\
\text { take many days, and } \\
\text { supervisor frowns on use } \\
\text { of days }\end{array}$ \\
\hline Job mastery & & Most items & $\begin{array}{l}\text { Getting the job done items } \\
\text { changed to doing enough } \\
\text { work and feeling self- } \\
\text { confident about work; } \\
\text { getting along with others } \\
\text { items reduced to lack of } \\
\text { friendly relationships at } \\
\text { work; planning next } \\
\text { career step items changed } \\
\text { to considering what work } \\
\text { you could do and having } \\
\text { drive/energy for } \\
\text { promotions }\end{array}$ \\
\hline \multirow[t]{2}{*}{ Job satisfaction } & $\begin{array}{l}\text { Feeling unhappy with job because of } \\
\text { your health }\end{array}$ & Most items & $\begin{array}{l}5 \text { items were retained but } \\
\text { posed as potential } \\
\text { barriers, lack of the } \\
\text { following: feeling of } \\
\text { accomplishment, adequate } \\
\text { pay, steady employment, } \\
\text { health } \\
\text { insurance/retirement } \\
\text { benefits }\end{array}$ \\
\hline & $\begin{array}{l}\text { New barrier category added: getting ready } \\
\text { for work; includes getting out of bed; } \\
\text { extra time needed for dressing, etc.; } \\
\text { getting family members ready; doing } \\
\text { stairs at home } \\
\text { New barrier category added: traveling to } \\
\text { from, or for work, includes driving } \\
\text { issues; other commuting issues; stress } \\
\text { of getting to work on time; travel for } \\
\text { business; lifting/carrying things } \\
\text { New barrier category added: balance } \\
\text { between work and home life, includes } \\
\text { getting household work done; lack of } \\
\text { family support; doing family, social } \\
\text { and recreational activities; self-care }\end{array}$ & & \\
\hline
\end{tabular}

patient. One physical therapist reported feeling unhelpful to a patient unless something physical was done, e.g., therapeutic exercise. Although many patients reportedly appreciated being given the list of resources for further help, one therapist felt that referring the patient elsewhere for help was "passing the buck."

\section{DISCUSSION}

Using input from patients, rehabilitation professionals, and published literature, we developed a health-related work barrier assessment tool, the WES-RC, for use by health professionals with patients with rheumatic condi- 


\begin{tabular}{|c|c|c|}
\hline Question & $\begin{array}{c}\text { First } \\
\text { administration }\end{array}$ & $\begin{array}{c}\text { Second } \\
\text { administration }\end{array}$ \\
\hline How well did the WES-RC address the patients' work problems?† & $8.5(6-10)$ & $9.0(8-10)$ \\
\hline How user friendly was the WES-RC?‡ & $8.6(7-10)$ & $9.1(8-10)$ \\
\hline How hard was it to develop solutions for the patients' problems?§ & $4.3(1-7)$ & $4.6(1-8)$ \\
\hline \multicolumn{3}{|l|}{ Was the time it took to administer the WES-RC, no. (\%) } \\
\hline Too long & $2(20)$ & \\
\hline About right & $8(80)$ & 8 (100)I \\
\hline Too short & & \\
\hline Actual administration time, minutes & $44(29-60)$ & $43(25-60)$ \\
\hline $\begin{array}{l}\text { * Values are the mean (range) unless indicated otherwise. } \\
\text { + Scale of } 1-10 \text { where } 10=\text { completely addressed all problems. } \\
\text { ₹ Scale of } 1-10 \text { where } 10=\text { very user friendly. } \\
\text { \& Scale of } 1-10 \text { where } 10=\text { very hard. } \\
\text { II } 2 \text { responses missing. }\end{array}$ & & \\
\hline
\end{tabular}

tions. The tool is a modified form of the WES, a structured interview tool (10). Use of the WES-RC could be useful to employed persons with a wide variety of rheumatic conditions who are experiencing, or are at risk for, work disability. Physical and occupational therapists favorably rated the tool's coverage of rheumatic condition work barriers. The WES-RC was efficient to use, and administration time was 30-60 minutes, which therapists rated as appropriate in $89 \%$ of administrations.

Studies of risk factors for arthritis-related work disability, and a recent qualitative study, offer face validity for the tool's barrier content. The barriers of the physical demands of jobs, extra time needed to get ready in the morning, and commuting difficulty have been found to increase risk for arthritis work disability (11). In a recent qualitative study by Lacaille et al (22), participants described disability identity and disclosure issues that were similar to those cited by our patient subjects as difficulties they faced in maintaining employment.

Use of the WES-RC appears to be relevant to the practice of physical and occupational therapy. Eighty percent of therapist administration experiences were positive. $\mathrm{Pa}$ tients' barriers were readily identified, and solutions for barriers were formed without difficulty for more than $50 \%$ of the patients. However, therapists' solution formation was difficult for $45 \%$ of patients, and we judged the therapists' solutions as insufficient for $35 \%$ of patients. These findings could suggest that physical and occupational therapists in general outpatient practice need additional information about accommodations and other solutions for common rheumatic condition work barriers. These therapists may especially need help when addressing disability identity and disclosure issues, which therapist subjects perceived as being psychosocial. Are such issues relevant to physical therapy practice in particular? We argue that they are, given that these issues are likely raised by common therapy practices such as prescribing the use of a cane.
Certain findings from our study are limited by small sample sizes. Only 2 male patients participated, so barriers related to jobs typically held by men, particularly heavymanual labor jobs, may be missing on the WES-RC. The 16 different job actions listed in the physical job demand section of the original WES were derived from a wide variety of jobs (23). We retained all these actions except for "hearing well" and added the following actions: moving objects, reaching, bending, squatting, picking things up from low places, and carrying. Space to describe other barriers is also provided. Therefore, we believe the WES-RC has a more comprehensive list of physical job demands than the original WES. Given the small number of therapist subjects, the findings from therapists are exploratory, and need to be confirmed in a larger sample.

The WES-RC tool appears to be feasible for rheumatology patients and for use by physical and occupational therapists. Work is underway to collect information about solutions for common work barriers and to test whether provision of such information improves solution formation by health professionals.

\section{ACKNOWLEDGMENTS}

The authors wish to thank Faye Cochrane for her contribution to acquisition of data, and the therapists at the Boston Medical Center and at the Tufts Medical Center, Boston, MA for their participation in this study.

\section{AUTHOR CONTRIBUTIONS}

All authors were involved in drafting the article or revising it critically for important intellectual content, and all authors approved the final version to be submitted for publication. Dr. Allaire had full access to all of the data in the study and takes responsibility for the integrity of the data and the accuracy of the data analysis.

Study conception and design. Allaire.

Acquisition of data. Allaire.

Analysis and interpretation of data. Allaire, Keysor. 


\section{REFERENCES}

1. Theis KA, Murphy L, Hootman JM, Helmick CG, Yelin E. Prevalence and correlates of arthritis-attributable work limitation in the US population among persons ages 18-64: 2002 National Health Interview Survey Data. Arthritis Rheum 2007;57:355-63.

2. Allaire S, Li W, LaValley M. Reduction of job loss in persons with rheumatic diseases receiving vocational rehabilitation: a randomized controlled trial. Arthritis Rheum 2003;48: 3212-8.

3. Allaire SH, Partridge AJ, Andrews HF, Liang MH. Management of work disability resources for vocational rehabilitation. Arthritis Rheum 1993;36:1663-70.

4. Varekamp I, Haafkens JA, Detaille SI, Tak PP, van Dijk FJ. Preventing work disability among employees with rheumatoid arthritis: what medical professionals can learn from the patients' perspective. Arthritis Rheum 2005;53:965-72.

5. Bohr PC. Work analysis. In: King P, editor. Sourcebook of occupational rehabilitation. New York: Plenum; 1998. p. 22946.

6. Rumrill PD, Bellini JL, Koch LC. Vocational assessment in the Americans with Disabilities Act era. In: Emerging issues in rehabilitation counseling: perspectives on the new millennium. Springfield (IL): Charles C. Thomas; 2001. p. 89-126.

7. Village J, Backman CL, Lacaille D. Evaluation of selected assessment tools for use in promoting job accommodation for people with arthritis. Work 2008;31:145-57.

8. Gilworth G, Chamberlain MA, Harvey A, Woodhouse A, Smith J, Smyth MG, et al. Development of a work instability scale for rheumatoid arthritis. Arthritis Rheum 2003;49:34954.

9. Backman CL, Village J, Lacaille D. The Ergonomic Assessment Tool for Arthritis: development and pilot testing. Arthritis Rheum 2008;59:1495-503.

10. Roessler RT, Reed CA, Rumrill PD Jr. The work experience survey (WES) manual. Hot Springs (AR): Arkansas University; 1995.

11. Verstappen SM, Bijlsma JW, Verkleij H, Buskens E, Blaauw AA, ter Borg EJ, et al. Overview of work disability in rheuma- toid arthritis as observed in cross-sectional and longitudinal surveys. Arthritis Rheum 2004;51:488-97.

12. Strauss A, Corbin J. Grounded theory in practice. Thousand Oaks (CA): Sage; 1997.

13. Allaire S, Li W, LaValley M. Work barriers experienced and job accommodations used by persons with arthritis and other rheumatic diseases. Rehabil Couns Bull 2003;46:147-56.

14. Mancuso CA, Paget SA, Charlson ME. Adaptations made by rheumatoid arthritis patients to continue working: a pilot study of workplace challenges and successful adaptations. Arthritis Care Res 2000;13:89-99.

15. Poole JL, Atanasoft G, Pelsor JC, Sibbitt WL, Brooks WM. Relationship between person and health factors in job characteristics in women with systemic lupus erythematosus. Work 2007;28:95-100.

16. Backman CL, Kennedy SM, Chalmers A, Singer J. Participation in paid and unpaid work by adults with rheumatoid arthritis. J Rheumatol 2004;31:47-57.

17. Lacaille D, Sheps S, Spinelli JJ, Chalmers A, Esdaile J. Identification of modifiable work-related factors that influence the risk of work disability in rheumatoid arthritis. Arthritis Rheum 2004;51:843-52.

18. Detaille SI, Haafkens JA, van Dijk FJ. What employees with rheumatoid arthritis, diabetes mellitus and hearing loss need to cope at work. Scand J Work Environ Health 2003;29:13442.

19. Howden S, Jones D, Martin D, Nicol M. Employment and chronic non-cancer pain: insights into work retention and loss. Work 2003;20:199-204.

20. Fifield J, Reisine ST, Grady K. Work disability and the experience of pain and depression in rheumatoid arthritis. Soc Sci Med 1991;5:579-85.

21. Robinson HS, Walters K. Patterns of work: rheumatoid arthritis. Int Rehab Med 1979;1:121-5.

22. Lacaille D, White MA, Backman CL, Gignac MA. Problems faced at work due to inflammatory arthritis: new insights gained from understanding patients' perspective. Arthritis Rheum 2007;57:1269-79.

23. Greenwood R, Johnson V, Wilson J, Schriner K. Rehab mark. Hot Springs (AR): Arkansas University; 1988.

DOI 10.1002/art.24805

\section{Submissions Invited for Themed Issue of Arthritis Care \& Research: Drug Safety in the Rheumatic Diseases}

Arthritis Care \& Research is soliciting manuscripts for a themed issue addressing drug safety in the treatment of rheumatic diseases, including but not limited to biologic agents. Manuscripts covering a broad range of topics related to the major theme are invited; for example, update on safety issues related to a specific drug or biologic agent, issues related to classes of treatments (e.g., anti-tumor necrosis factors [anti-TNFs]) and types of events (e.g., opportunistic infections in patients receiving anti-TNF agents), and issues related to different methodologies for assessing safety. Submissions may also describe more general issues related to treatment safety such as new or evolving methods of assessing or discussing safety, or benefit or safety/ benefit ratio with patients. Manuscripts from a wide range of disciplines relevant to safety are welcome.

The issues will include regular submissions as well, but a certain number of pages will be reserved for manuscripts accepted in response to this solicitation. Manuscripts will be subject to the usual review process and all types of manuscripts (e.g., original articles, contributions from the field, case studies, trainee rounds, reviews) are included in this solicitation.

The deadline for submission is October 1, 2009. For further information, contact the editors of Arthritis Care \& Research, Edward H. Yelin, PhD (Ed.Yelin@ucsf.edu) or Patricia P. Katz, PhD (Patti.Katz@ucsf.edu). 